both resemble the otherwise quite distinct $A$. dimidiatum apicale. In yakima, however, the apical third of the anterior wings is black.

True A. aquabile, of which I examined a very long series, is readily separated by the apical black of the wings, which is conspicuously less intense, having its inner side less well defined, and projecting toward the base of the wing in the middle, the shape of the inner margin being roughly that of a broad V. The hudsonicum form, which seems weakly characterised, goes with axquabile.

Possibly A. yakima should be considered a valid species, and coloradicum a subspecies of it.

The type of coloradicum has been placed in the National Museum.

\title{
DIDACTYLOMYIA CAPITATA SP. NOV.
}

\author{
By E. P. Felt, \\ Albany, N. Y.
}

The peculiar male described below was collected by Mr. Owen Bryant in August, 1907, either at North Adams, Mass., or on Greylock Mountain. It is closely allied to $D$. longimana from which it is most easily separated by its slightly smaller size, the capitate terminal clasp segment and the relatively longer harpes.

Didactylomyia capitata sp. nov.

Male. Length $1.25 \mathrm{~mm}$. Antennæ probably a little longer than the body, sparsely haired, the stems white, the basal enlargement dark brown; probably fourteen or sixteen segments, the fifth with a stem one-fourth longer than the cylindric basal enlargement, which latter has a length two and one-half times its diameter. Palpi; the first segment irregular, with a length about twice its diameter, the second lanceolate, with a length nearly four times its diameter, the third a little shorter and more slender than the second, the fourth about as long as the third, somewhat dilated. Mesonotum, scutellum and postscutellum mostly reddish brown, the scutellum slightly yellowish apically. Abdomen yellowish, reddish basally. Halteres and legs pale yellowish white. Genitalia; basal and terminal clasp segments both greatly produced, the latter decidedly capitate apically; dorsal plate short, broad, deeply and narrowly incised, the sparse setose lobes narrowly rounded; ventral plate short, broad, broadly and roundly emarginate. Harpes, basal portion broad, obliquely truncate, the inner angles produced as a somewhat irregular, capitate process as long as the basal portion and extending to the tip of the style, which latter is stout, tapering and narrowly rounded. Type Cecid. 1439. 

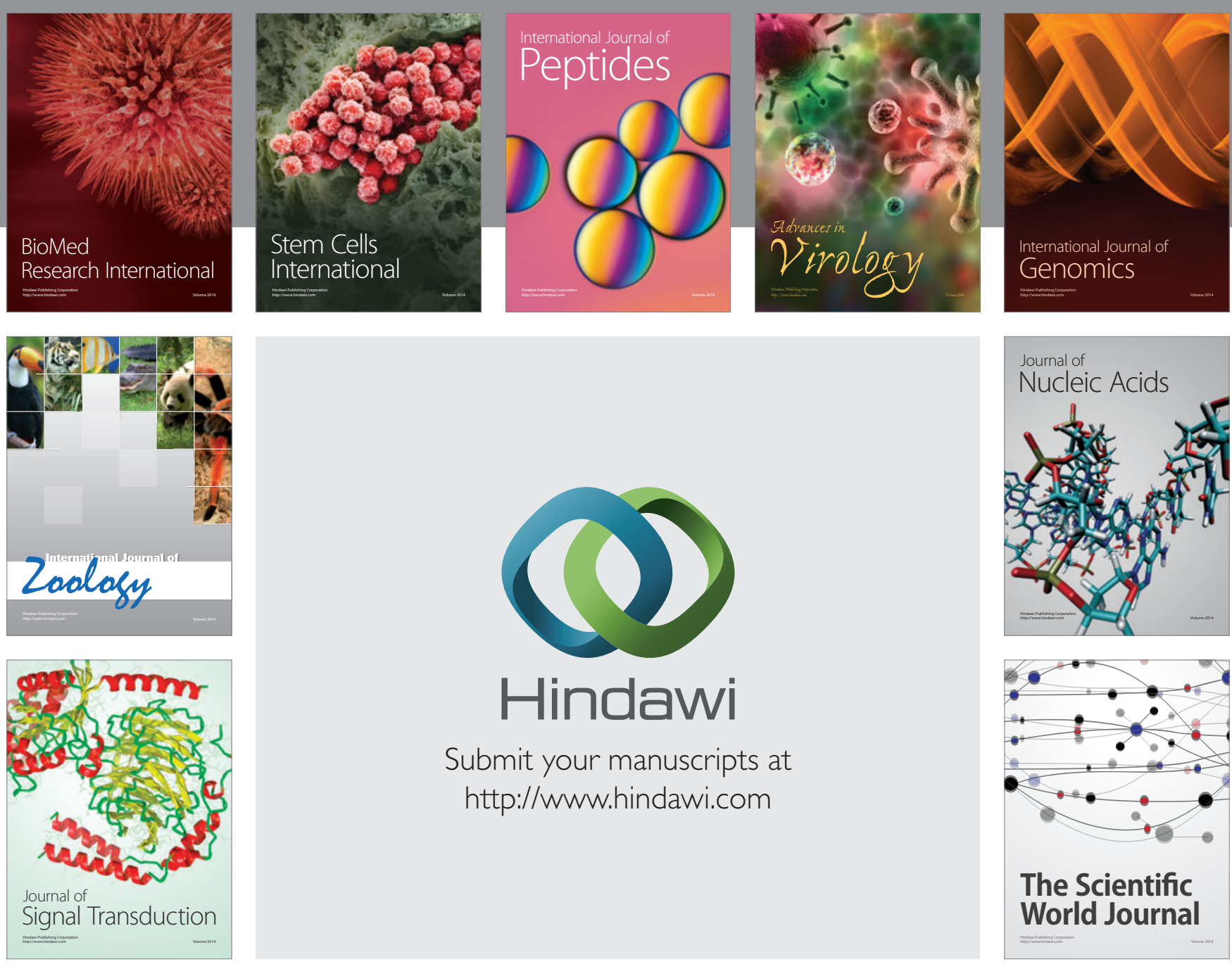

Submit your manuscripts at

http://www.hindawi.com
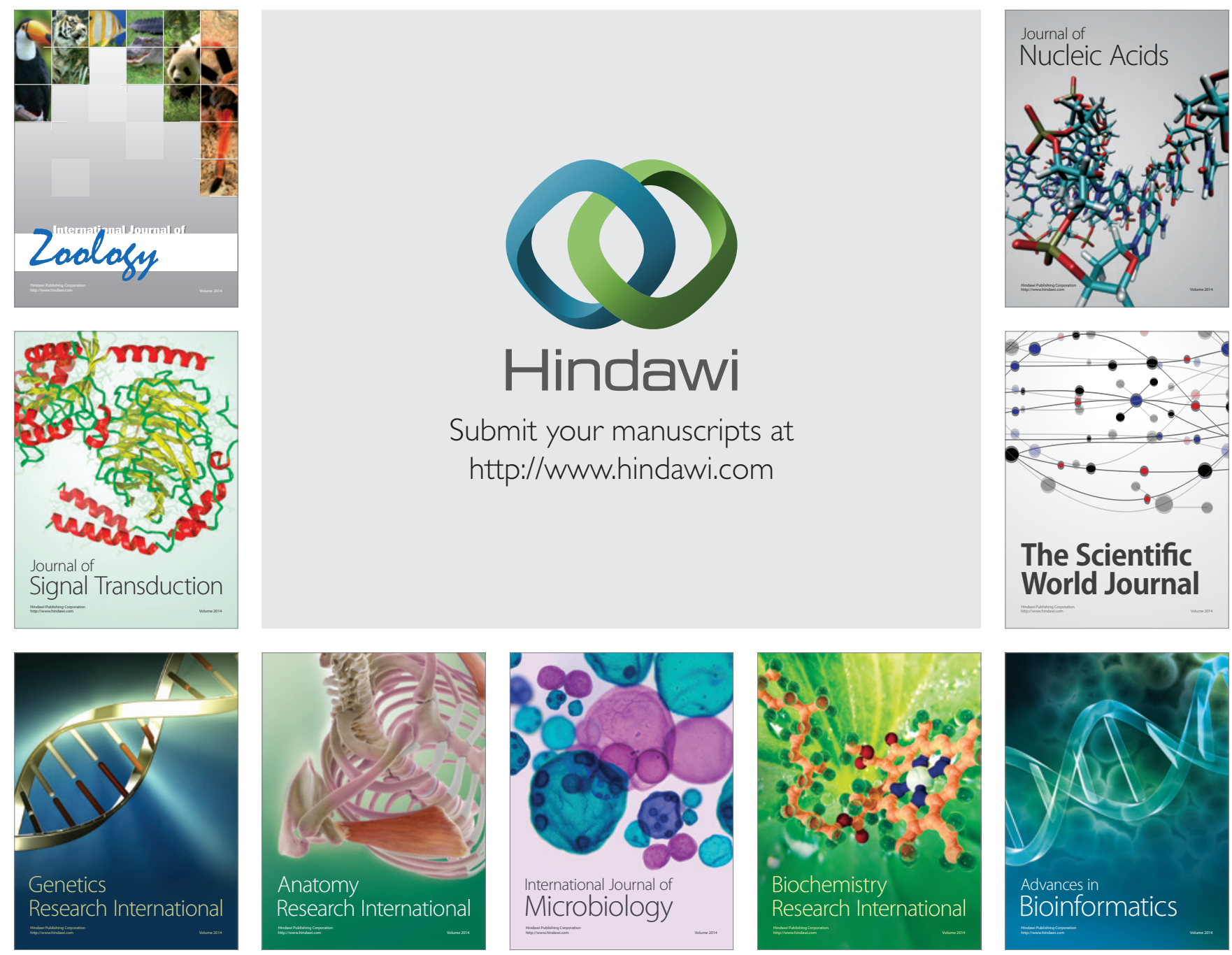

The Scientific World Journal
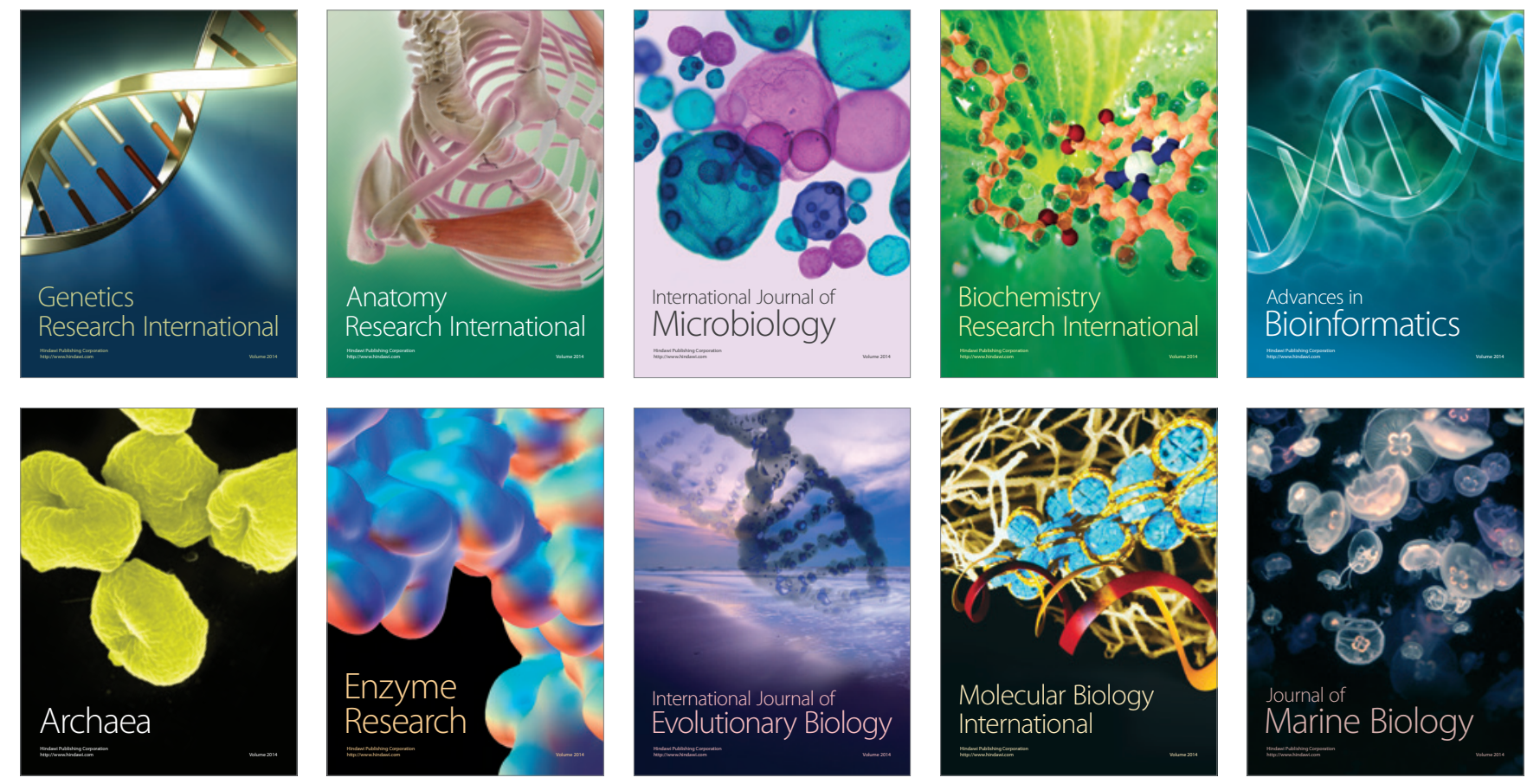